\title{
COMMERCIAL DRIVER MEDICAL EXAMS: RELATIONSHIPS BETWEEN BODY MASS INDEX AND COMORBID CONDITIONS
}

Matthew S. Thiese ${ }^{1}$, Gary Moffitt ${ }^{2}$, Richard J. Hanowski ${ }^{3}$, Stefanos N. Kales ${ }^{4}$, Richard J. Porter ${ }^{5}$, and Kurt T. Hegmann ${ }^{1}$

${ }^{1}$ From the Rocky Mountain Center for Occupational \& Environment Health (Drs Thiese, and Hegmann), Department of Family and Preventive Medicine, School of Medicine, University of Utah, Salt Lake City, Utah, USA

${ }^{2}$ Arkansas Occupational Health Clinic (Dr Moffitt), Springdale, Arkansas, USA

${ }^{3}$ Center for Truck and Bus Safety (Dr Hanowski), Virginia Tech Transportation Institute, Blacksburg, Virginia, USA

${ }^{4}$ Department of Environmental Health (Dr Kales), School of Public Health, Harvard, Cambridge, Massachusetts, USA

${ }^{5}$ Utah Traffic Lab (Dr Porter), Department of Civil \& Environmental Engineering, University of Utah, Salt Lake City, Utah, USA

Kurt.hegmann@hsc.utah.edu,gmoffitt@aohconline.com,rhanowski@vtti.vt.edu, skales@hsph.harvard.edu \& richard.jon.porter@utah.edu,

Summary: There are an estimated 5.7 million Commercial Motor Vehicle (CMV) drivers in the United States in 2012. Health and Safety of CMV drivers are of high consequence group because of: occupational risks from the size and speed of their vehicles, frequently poor health status, poor health care utilization, and the large impact of truck crashes on public health and safety. CMV drivers pass a commercial driver medical examination (CDME) to maintain licensure. CDME examiners document multiple potentially disqualifying health conditions. CMV drivers reportedly have poor health status, which may be attributed to lifestyle and occupational factors (e.g., improper diet, inadequate physical activity, poor sleep hygiene, shift work), yet few data are reported analyzing relative importance and relationships of these factors. Methods- CDMEs conducted between 2005 and 2012 among 88,246 commercial drivers were analyzed. Associations between measured Body Mass Index (BMI) categories and CDME findings, as well as driver certification were examined. Results- $53.3 \%$ of drivers were obese (BMI>30.0 $\mathrm{kg} / \mathrm{m}^{2}$ ) with half of those being morbidly obese $\left(\right.$ BMI $\left.>35.0 \mathrm{~kg} / \mathrm{m}^{2}\right)$. After adjustment for age and gender, obese drivers were statistically significantly less likely to be certified for the full 2 year period and significantly more likely to report many factors including heart disease, hypertension, diabetes mellitus, nervous disorders, sleep disorders, and chronic low back pain (all $\mathrm{p}<0.0001$ ). Conclusions$\mathrm{BMI}$ is related to many factors, some of which have been associated with increased crash risk. BMI screening may be a useful tool. Interventions for BMI reduction may have an impact on comorbidities.

\section{OBJECTIVE}

The goal of this report is to assess relationships between Body Mass Index (BMI) and both comorbid conditions and driver certification as part of the Commercial Driver Medical Exam (CDME) within a large sample of truck drivers from across the United States. 


\section{METHODS}

The University of Utah Institutional Review Board approved this study. Data was obtained from a private company that provides a web-based platform for recording CMDE findings Commercial Driver Medical Exam performed by numerous examiners on CMV drivers licensed in all 48 lower states. CDMEs from drivers in the database are employed by both private carriers and independent owner/operator drivers. Most drivers are over-the-road or long-haul drivers.

CDMEs are required for licensure of commercial drivers. At the completion of each examination, the examiner determines whether the driver meets the requirements for unrestricted certification (up to 2 years), shortened certification, or does not meet the medical requirements. CDMEs are directly entered to an electronic database which helps guarantee data integrity and completeness. CDMEs performed between January 1, 2005 to October 31, 2012 were analyzed and included: demographics, medical history, measured height, weight and blood pressure, urinalysis, and other medical exams. If drivers have multiple consecutive CDMEs in the database, only the first CDME was analyzed, and all others were excluded.

A total of 96,591 CDMEs were extracted from the database, and 8,345 (8.6\%) were excluded because of $2^{\text {nd }}(n=7,939)$ or $3^{\text {rd }}$ exam $(n=6)$ or incomplete data or erroneous BMI measures $\left(\mathrm{n}=400, \mathrm{BMI}<10.5 \mathrm{~kg} / \mathrm{m}^{2}\right.$ or $\left.>100 \mathrm{~kg} / \mathrm{m}^{2}\right)$.

All analyses were conducted using SAS 9.3 (SAS Institute, Cary NC). Data were stratified by BMI category into Underweight (BMI $<18.5 \mathrm{~kg} / \mathrm{m}^{2}$ ), Normal weight (BMI $\geq 18.5 \mathrm{~kg} / \mathrm{m}^{2}$ to $<25.0$ $\mathrm{kg} / \mathrm{m}^{2}$ ), Overweight (BMI $\geq 25.0 \mathrm{~kg} / \mathrm{m}^{2}$ to $<30.0 \mathrm{~kg} / \mathrm{m}^{2}$ ), Obese $\left(\mathrm{BMI} \geq 30 \mathrm{~kg} / \mathrm{m}^{2}\right.$ to $<35 \mathrm{~kg} / \mathrm{m}^{2}$ ), and Morbidly Obese $\left(\mathrm{BMI} \geq 35 \mathrm{~kg} / \mathrm{m}^{2}\right)$. Mean and standard deviations are presented. Categorical variables were analyzed using Fischer's exact test and continuous variables were analyzed using the Kruskal-Wallis test as data were not normally distributed. Logistic regression was used to quantify the magnitude and direction of association between BMI category and CDME measures. Odds ratio (OR) and 95\% confidence interval $(95 \% \mathrm{CI})$ are adjusted for age and gender in a multivariate logistic regression.

\section{RESULTS}

Among the 88,246 drivers eligible for analysis, the majority of participants were obese with a $\mathrm{BMI} \geq 30.0 \mathrm{~kg} / \mathrm{m}^{2}(53.2 \%)$. The proportions with a BMI $\geq 35.0$ and $\geq 40.0 \mathrm{~kg} / \mathrm{m}^{2}$ were $26.6 \%$ 
and $12.1 \%$ respectively (data not shown).

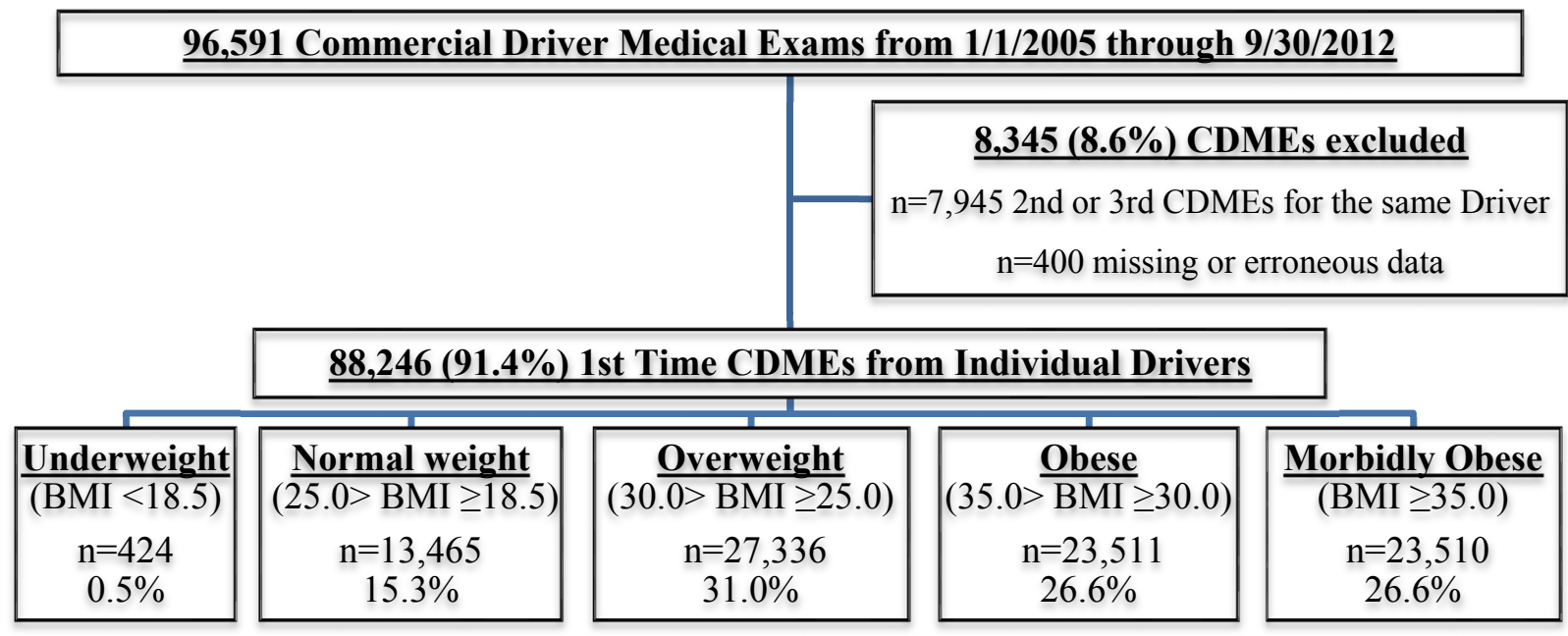

Figure 1. Flow Chart of Commercial Driver Medical Exam Data from Road Ready

Demographic and population descriptive statistics stratified by BMI category can be found in Table 1. Among other differences, overweight, obese, and morbidly obese drivers are statistically significantly less likely to be certified for the maximum of 2 years. Relationships between gender and BMI category were non-linear with a higher frequency of females in the underweight and morbidly obese categories. The proportion of participants who were certified or disqualified was statistically and meaningfully different across BMI categories.

Table 1. Demographic Data from Commercial Driver Medical Exam Stratified by BMI Categories

\begin{tabular}{|c|c|c|c|c|c|c|c|c|c|c|c|c|c|c|}
\hline & & & \multicolumn{2}{|c|}{ Under- } & \multicolumn{2}{|c|}{ Normal } & \multicolumn{2}{|c|}{ Overweight } & \multicolumn{2}{|c|}{ Obese } & \multicolumn{2}{|c|}{ Morbidly } & \multicolumn{2}{|c|}{ Total } \\
\hline Age (year) & & $\begin{array}{l}\text { Mean } \\
(\mathrm{SD})\end{array}$ & \multicolumn{2}{|c|}{$42.3(11.5)$} & \multicolumn{2}{|c|}{$44.6(11.1)$} & \multicolumn{2}{|c|}{$46.9(10.4)$} & \multicolumn{2}{|c|}{$46.9(10.1)$} & \multicolumn{2}{|c|}{$45.1(10.0)$} & \multicolumn{2}{|c|}{$46.0(10.4)$} \\
\hline Systolic Pres & & $\begin{array}{l}\text { Mean } \\
(\mathrm{SD})\end{array}$ & \multicolumn{2}{|c|}{$116.8(13.0)$} & \multicolumn{2}{|c|}{$121.1(13.0)$} & \multicolumn{2}{|c|}{$125.7(13.0)$} & \multicolumn{2}{|c|}{$128.1(12.7)$} & \multicolumn{2}{|c|}{$130.3(12.6)$} & \multicolumn{2}{|c|}{$126.8(13.2)$} \\
\hline $\begin{array}{l}\text { Diastolic } \\
\text { Pressure }\end{array}$ & & $\begin{array}{l}\text { Mean } \\
\text { (SD) }\end{array}$ & \multicolumn{2}{|c|}{$74.6(9.0)$} & \multicolumn{2}{|c|}{77.4 (8.5) } & \multicolumn{2}{|c|}{$80.5(8.0)$} & \multicolumn{2}{|c|}{$82.0(7.7)$} & \multicolumn{2}{|c|}{$83.1(7.5)$} & \multicolumn{2}{|c|}{$81.1(8.1)$} \\
\hline \multirow{2}{*}{ Gender } & \multicolumn{2}{|c|}{ Male } & 390 & $92.0 \%$ & 12878 & $95.6 \%$ & 26450 & $96.8 \%$ & 22584 & $96.1 \%$ & 22057 & $93.8 \%$ & 84359 & $95.6 \%$ \\
\hline & \multicolumn{2}{|c|}{ Female } & 34 & $8.0 \%$ & 587 & $4.4 \%$ & 886 & $3.2 \%$ & 927 & $3.9 \%$ & 1453 & $6.2 \%$ & 3887 & $4.4 \%$ \\
\hline \multirow{4}{*}{$\begin{array}{l}\text { Certification } \\
\text { Time }\end{array}$} & $\mathrm{Qu}$ & fied & & $84.4 \%$ & 10940 & $81.2 \%$ & 19417 & $71.0 \%$ & 14470 & $61.5 \%$ & 10870 & $46.2 \%$ & 56055 & $63.5 \%$ \\
\hline & $\mathrm{Pe}$ & & & $7.8 \%$ & 1748 & $13.0 \%$ & 6145 & $22.5 \%$ & 7261 & $30.9 \%$ & 9942 & $42.3 \%$ & 25129 & $28.5 \%$ \\
\hline & $\mathrm{Te}$ & orary & 15 & $3.5 \%$ & 301 & $2.2 \%$ & 798 & $2.9 \%$ & 763 & $3.2 \%$ & 1076 & $4.6 \%$ & 2953 & $3.3 \%$ \\
\hline & & Ialified & 18 & $4.2 \%$ & 476 & $3.5 \%$ & 976 & $3.6 \%$ & 1017 & $4.3 \%$ & 1622 & $6.9 \%$ & 4109 & $4.7 \%$ \\
\hline
\end{tabular}


Table 2. Odds Ratio and 95\% Confidence Interval for Associations between Health History from Commercial Driver Medical Exam and Between BMI Categories, adjusted for Age and Gender

\begin{tabular}{|c|c|c|c|c|c|}
\hline \multirow[b]{2}{*}{ Variable } & Under-weight & Normal weight & Overweight & Obese & Morbidly Obese \\
\hline & OR $(95 \% \mathrm{CI})$ & OR $(95 \% \mathrm{CI})$ & OR $(95 \% \mathrm{CI})$ & OR $(95 \% \mathrm{CI})$ & OR $(95 \% \mathrm{CI})$ \\
\hline $\begin{array}{c}\begin{array}{c}\text { Certification Less than } 2 \\
\text { years }\end{array} \\
\end{array}$ & $0.92(0.69,1.21)$ & 1.00 (Ref.) & $1.61(1.53,1.70)$ & $2.61(2.48,2.75)$ & $\begin{array}{c}6.00(5.69 \\
6.33) \\
\end{array}$ \\
\hline Injury/illness past 5 years & $1.15(0.89,1.48)$ & 1.00 (Ref.) & $1.19(1.13,1.26)$ & $1.44(1.36,1.52)$ & $\begin{array}{c}1.75(1.66, \\
1.85)\end{array}$ \\
\hline Head/Brain Injuries & $2.21(0.89,5.49)$ & 1.00 (Ref.) & $1.16(0.88,1.53)$ & $1.02(0.76,1.36)$ & $\begin{array}{c}1.32(1.01 \\
1.74) \\
\end{array}$ \\
\hline Heart Disease & $1.52(0.66,3.50)$ & 1.00 (Ref.) & $1.46(1.21,1.76)$ & $2.11(1.76,2.54)$ & $\begin{array}{c}2.49(2.08 \\
3.00)\end{array}$ \\
\hline Heart Disease Meds & $\mathrm{N} / \mathrm{A}$ & 1.00 (Ref.) & $1.48(1.10,1.99)$ & $2.04(1.52,2.72)$ & $\begin{array}{c}2.48(1.86 \\
3.31)\end{array}$ \\
\hline Heart Surgery & $1.34(0.49,3.70)$ & 1.00 (Ref.) & $1.50(1.21,1.86)$ & $2.20(1.78,2.71)$ & $\begin{array}{c}2.35(1.90 \\
2.91)\end{array}$ \\
\hline High Blood Pressure & $0.76(0.48,1.21)$ & 1.00 (Ref.) & $2.00(1.85,2.16)$ & $3.61(3.35,3.89)$ & $\begin{array}{c}6.94(6.44 \\
7.48)\end{array}$ \\
\hline Using Medications & $0.64(0.34,1.22)$ & 1.00 (Ref.) & $1.99(1.81,2.19)$ & $3.22(2.93,3.54)$ & $\begin{array}{c}5.74(5.23 \\
6.30)\end{array}$ \\
\hline Lung Disease & $1.81(1.10,2.99)$ & 1.00 (Ref.) & $0.94(0.81,1.08)$ & $1.09(0.95,1.26)$ & $\begin{array}{c}1.37(1.19 \\
1.57)\end{array}$ \\
\hline Shortness of Breath & $3.26(1.74,6.11)$ & 1.00 (Ref.) & $0.69(0.55,0.88)$ & $0.97(0.77,1.22)$ & $\begin{array}{c}1.47(1.19 \\
1.83) \\
\end{array}$ \\
\hline Digestive Problems & $1.79(0.87,3.68)$ & 1.00 (Ref.) & $1.22(1.01,1.48)$ & $1.57(1.30,1.89)$ & $\begin{array}{c}1.76(1.46 \\
2.12) \\
\end{array}$ \\
\hline Diabetes Mellitus & $1.02(0.50,2.08)$ & 1.00 (Ref.) & $2.34(2.06,2.66)$ & $4.15(3.66,4.71)$ & $\begin{array}{c}7.99(7.06 \\
9.05)\end{array}$ \\
\hline Controlled with Diet & $1.30(0.57,2.97)$ & 1.00 (Ref.) & $2.33(1.97,2.75)$ & $3.96(3.36,4.66)$ & $\begin{array}{c}7.47(6.37 \\
8.77)\end{array}$ \\
\hline Controlled with Pills & $0.65(0.24,1.77)$ & 1.00 (Ref.) & $2.42(2.09,2.80)$ & $4.26(3.69,4.91)$ & $\begin{array}{c}8.30(7.21 \\
9.54) \\
\end{array}$ \\
\hline Nervous Disorders & $2.53(1.45,4.39)$ & 1.00 (Ref.) & $1.31(1.10,1.56)$ & $1.56(1.31,1.85)$ & $\begin{array}{c}1.86(1.57 \\
2.20)\end{array}$ \\
\hline Using Medications & $2.04(0.89,4.68)$ & 1.00 (Ref.) & $1.37(1.08,1.74)$ & $1.68(1.32,2.12)$ & $\begin{array}{c}2.02(1.60 \\
2.54) \\
\end{array}$ \\
\hline Sleep Disorders & $\begin{array}{c}3.80(1.35 \\
10.73) \\
\end{array}$ & 1.00 (Ref.) & $2.29(1.60,3.28)$ & $5.49(3.89,7.73)$ & $\begin{array}{c}28.59(20.53 \\
39.79) \\
\end{array}$ \\
\hline Spinal Injury or Disease & $0.89(0.33,2.41)$ & 1.00 (Ref.) & $1.18(0.97,1.42)$ & $1.28(1.06,1.55)$ & $\begin{array}{c}1.34(1.10 \\
1.62) \\
\end{array}$ \\
\hline Chronic Low Back Pain & $2.08(0.84,5.15)$ & 1.00 (Ref.) & $1.20(0.92,1.56)$ & $1.30(1.00,1.70)$ & $\begin{array}{c}1.36(1.05 \\
1.77) \\
\end{array}$ \\
\hline Monocular Vision & $2.75(0.99,7.66)$ & 1.00 (Ref.) & $0.89(0.63,1.26)$ & $0.66(0.45,0.98)$ & $\begin{array}{c}0.73(0.50 \\
1.06)\end{array}$ \\
\hline Requires Vision Correction & $1.26(1.03,1.54)$ & 1.00 (Ref.) & $1.02(0.98,1.06)$ & $1.08(1.03,1.13)$ & $\begin{array}{c}1.30(1.24 \\
1.35)\end{array}$ \\
\hline
\end{tabular}


Multiple statistically significant relationships between BMI categories and CDME health history questions were found (Table 2). Overweight, obese and morbidly obese CMV drivers were less likely to be certified for the full 2 year period, report having had a seizure, and have monocular vision, after adjustment for age and gender Conversely, increasing obesity was associated with CMV drivers having sleep disorders, lung disease, shortness of breath, digestive problems, diabetes mellitus, nervous disorders, spinal injury or disease, chronic low back pain, having had an injury or illness in the past 5 years, head or brain injuries, heart disease, taking medication for heart disease, had heart surgery, hypertension, to be taking medication for hypertension, and requiring vision correction. In these data, BMI categories had many nonlinear relationships, where CMV drivers in both low and high BMI categories having statistically increased associations as compared to normal weight drivers. These nonlinear significant relationships were found for drivers reporting of lung disease, shortness of breath, having nervous disorders, having sleep disorders, and requiring vision correction after adjustment for age and gender. There were no statistically significant relationships reported between BMI category and eye disorders, ear disorders, muscular disease, kidney disease, liver disease, altered consciousness, fainting/dizziness, stroke or paralysis, missing extremities, frequent alcohol use, habit forming/narcotic drug use, or color blindness.

These analyses provide insight regarding the health and comorbidities of CMV drivers. One of the most meaningful results is the distribution of BMI within these data: $53.3 \%$ of the drivers were obese $\left(B M I \geq 30.0 \mathrm{~kg} / \mathrm{m}^{2}\right), 26.6 \%$ were severely obese $\left(\mathrm{BMI} \geq 35.0 \mathrm{~kg} / \mathrm{m}^{2}\right)$, and $12.1 \%$ were morbidly obese (BMI $\geq 40.0 \mathrm{~kg} / \mathrm{m}^{2}$ ). It is noteworthy that the findings from this study demonstrate substantial proportions of drivers are above any of the varying BMI screening threshold criteria for sleep apnea, a noted factor associated with drowsy driving, that range from 30.0-35.0 kg/m².(Administration, 2010; Board, 2010)

Although these analyses have underscored associations between health factors and BMI, processes whereby obesity or these health factors increase risk for crashes is not known. Associations between BMI and sleep disorders are recognized, and the subsequent on-road safety effects have been analyzed previously. Recent reports have found that obese CMV drivers involuntarily fall asleep more frequently compared to normal weight CMV drivers and have increased incidence of sleep apnea.(Ellen et al., 2006; Hartenbaum et al., 2006; Talmage, Hudson, Hegmann, \& Thiese, 2008; Tregear, Reston, Schoelles, \& Phillips, 2009) Relationships between health factors and BMI may represent modifiable means to prevent crashes, through the reduction in BMI. Although most of the CMV driver health literature relates to the connection between BMI and sleep apnea, these data establish that there are many disease states, including hypertension, cardiovascular disease, diabetes mellitus, psychological diseases, and spinal injuries/diseases, that are related to BMI categories in CMV drivers.

Anecdotally it is assumed that under-reporting and under-diagnosis of many factors is common. This is often attributed to the probability that the increasing comorbidities and certification are inversely related. Furthermore, under-reporting and under-diagnosis is believed not to occur by chance but occurs in relation to BMI, with under-reporting more likely to occur among obese drivers. It is possible that the real relationships concerning BMI category and these factors are more robust than these analyses. 


\section{CONCLUSIONS}

Many CMV drivers in this study are obese $(53.3 \%)$ and $26.6 \%$ have a BMI over $35.0 \mathrm{~kg} / \mathrm{m}^{2}$. Multiple clinically meaningful and statistically significant relationships were found between CDME elements and BMI categories. These relationships include sleep disorders, spinal injuries or disease, diabetes mellitus, lung disease, shortness of breath, digestive problems, illness or injuries in the past 5 years, cardiovascular issues, and requiring vision correction. These results suggest influences of obesity are abundant and may be beyond those commonly recognized among CMV drivers.

\section{ACKNOWLEDGEMENTS}

This study has been funded by grants from the National Institute for Occupational Safety and Health (NIOSH/CDC), 5K01OH009794-01 and NIOSH Education and Research Center training grant T42/CCT810426-10. The CDC/NIOSH is not involved in the study design, data analyses or interpretation of the data.

\section{REFERENCES}

Administration, F. M. C. S. (2010). Evidence Reports' Executive Summaries and Medial Expert Panel Recommendations. http://www.fmcsa.dot.gov/regulations/medical/reports-howmedical-conditions-impact-driving: Department of Transportation Federal Motor Carrier Safety Adminstriation.

Administration, F. M. C. S. (2013 Monday, December 23, 2013 ). Commercial Motor Vehicle Facts March 2013 Retrieved April 14, 2014, 2014, from http://www.fmcsa.dot.gov/safety/data-and-statistics/commercial-motor-vehicle-facts$\%$ E2\%80\%93-march-2013

Backman, A. L. (1983). Health survey of professional drivers. Scand J Work Environ Health, 9(1), 30-35.

Board, D. o. T. F. M. C. S. A. M. R. (2010). The Medical Review Board (MRB) of the U.S. Department of Transportation's Federal Motor Carrier Safety Administration (FMCSA) was convened on January 6, 2010, in Washington, D.C. Meeting Summary (pp. 26).

Ellen, R., Marshall, S. C., Palayew, M., Molnar, F. J., Wilson, K. G., \& Man-Son-Hing, M. (2006). Systematic review of motor vehicle crash risk in persons with sleep apnea. J Clin Sleep Med, 2(2), 193-200.

Hartenbaum, N., Collop, N., Rosen, I. M., Phillips, B., George, C. F., Rowley, J. A., . . Strohl, K. (2006). Sleep Apnea and Commercial Motor Vehicle OperatorsStatement From the Joint Task Force of the American College of Chest Physicians, the American College of Occupational and Environmental Medicine, and the National Sleep Foundation. CHEST Journal, 130(3), 902-905.

Jones, D., \& Switzer-McIntyre, S. (2003). Falls from trucks: a descriptive study based on a workers compensation database. Work, 20(3), 179-184.

Leigh, J. P., \& Miller, T. R. (1998). Job-related diseases and occupations within a large workers' compensation data set. Am J Ind Med, 33(3), 197-211.

Lund, A. K., Preusser, D. F., Blomberg, R. D., \& Williams, A. F. (1988). Drug use by tractortrailer drivers. J Forensic Sci, 33(3), 648-661. 
Muscat, J. E., \& Wynder, E. L. (1995). Diesel exhaust, diesel fumes, and laryngeal cancer. Otolaryngol Head Neck Surg, 112(3), 437-440.

Robinson, C. F., \& Burnett, C. A. (2005). Truck drivers and heart disease in the United States, 1979-1990. Am J Ind Med, 47(2), 113-119.

Stoohs, R. A., Bingham, L. A., Itoi, A., Guilleminault, C., \& Dement, W. C. (1995). Sleep and sleep-disordered breathing in commercial long-haul truck drivers. [Research Support, NonU.S. Gov't

Research Support, U.S. Gov't, P.H.S.]. Chest, 107(5), 1275-1282.

Talmage, J. B., Hudson, T. B., Hegmann, K. T., \& Thiese, M. S. (2008). Consensus criteria for screening commercial drivers for obstructive sleep apnea: evidence of efficacy. [Research Support, U.S. Gov't, P.H.S.

Validation Studies]. J Occup Environ Med, 50(3), 324-329. doi: 10.1097/JOM.0b013e3181617ab8

Tregear, S., Reston, J., Schoelles, K., \& Phillips, B. (2009). Obstructive sleep apnea and risk of motor vehicle crash: systematic review and meta-analysis. Journal of clinical sleep medicine: JCSM: official publication of the American Academy of Sleep Medicine, 5(6), 573.

van Poppel, M. N., Koes, B. W., Deville, W., Smid, T., \& Bouter, L. M. (1998). Risk factors for back pain incidence in industry: a prospective study. Pain, 77(1), 81-86. 